\title{
The political economy of international factor mobility
}

\author{
Giovanni Facchini ${ }^{\mathrm{a}, *}$, Gerald Willmann ${ }^{\mathrm{b}}$

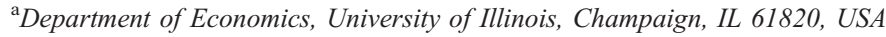 \\ ${ }^{\mathrm{b}}$ Department of Economics, Universität zu Kiel, 24098 Kiel, Germany
}

Received 5 January 2004; received in revised form 5 July 2004; accepted 28 October 2004

\begin{abstract}
We model the endogenous determination of policy towards international factor mobility. In a common agency setting, domestic interest groups bid for protection from the government and the incumbent politicians maximize a welfare function that depends both on domestic voters' welfare and contributions collected. We characterize equilibrium policies in the price space and show how the degree of complementarity among inputs determines the outcome. We establish a similar result for quotas, allowing for partial rent capturing. For the strategic environment under consideration, we also establish a general equivalence result between tariffs and quotas if capturing is complete.

(C) 2004 Elsevier B.V. All rights reserved.
\end{abstract}

Keywords: FDI; Migration; Political economy; Common agency

JEL classification: F21; F22; D72

\section{Introduction}

Economic theory suggests that the free international movement of production factors is efficient, but countries invariably use their sovereignty to restrict migration and influence the flows of foreign direct investment. Notwithstanding Lady Liberty's promise "Give me

* Corresponding author. Tel.: +1 217265 0644; fax: +1 2172446678.

E-mail addresses: facchini@uic.edu (G. Facchini), gerald@email.uni-kiel.de (G. Willmann). 
your tired, your poor, your huddled masses, yearning to breathe free," virtually no nation has ever adopted an "Open Door" policy towards international migration, regardless of ethnicity or national origin. Movements of capital, and in particular the flow of Foreign Direct Investment, have also been the object of government regulation. At times in the past they were severely restricted, whereas more recently they have been actively subsidized. ${ }^{1}$

There is substantial evidence regarding the role of pressure groups in shaping the attitude of governments towards factor mobility. Labor Unions have consistently played an important role in determining US migration policy. The enactment of the first legislative measure to systematically limit immigration from a specific country-the Chinese Exclusion Act of 1882-was the result of the efforts of the newly founded Federation of Organized Trade and Labor Unions. Similarly, the American Federation of Labor (AFL) played an important role in the introduction of the Literacy Test provision in the 1917 Immigration Act, with the explicit intent to "screen and reduce the inflow of unskilled workers in the U.S labor force" (Briggs (1998), page 125). More recently, the AFL-CIO supported measures to reduce illegal immigration, that culminated in the 1986 Immigration Reform and Control Act.

Complementarities among factors are important in understanding pressure group behavior. For instance, during a recent debate spurred by Senator Hollings' bill limiting FDI by foreign state-owned corporations, the president of the Communications Workers of America, Morton Bahr, was called to witness on the proposed takeover of Voicestream by Deutsche Telekom. In his testimony, he stresses how "In the telecommunication industry, the presence of Deutsche Telekom in our market-place could yield some substantial benefits to workers and consumers." ${ }^{2}$ Similarly, analyzing the recent surge in immigration into the United States, Goldsborough (2000) notes that "Immigration policy today is driven by businesses that need more workers — skilled and unskilled, legal and illegal [...] During the annual debate on H1-B visas two years ago, Silicon Valley executives trooped before Congress, warning of a Y2K computer disaster unless the number of H1-B visas was increased."

At the same time, competition for foreign direct investment has become a global phenomenon. Both advanced and developing countries offer large financial and fiscal incentives to attract foreign corporations. Examples abound-consider the automobile sector as a particularly revealing case in point. Recent estimates ${ }^{3}$ show that the incentives offered to attract new plants have risen from the roughly $\$ 4,000$ per job paid by Ohio to secure a Honda plant in 1980 to the $\$ 168,000$ per job paid by Alabama in 1993 to convince Daimler-Benz to build a factory near Tuscaloosa. Other countries hardly lag behind. Portugal, for instance, offered an even more substantial package to secure a large investment by Ford and Volkswagen in 1992 and the list could go on. We can summarize this evidence as follows: on the one hand, organized factors lobby governments for protection; on the other, complementarities between factors matter in determining the amount of protection that is granted in equilibrium.

\footnotetext{
1 See Oman (2000).

2 The full statement is available at http://www.com-notes.house.gov/ccchear/hearings 106.nsf.

${ }^{3}$ See Oman (2000), page 80 .
} 
Building on these stylized facts, we formulate what-to the best of our knowledge-is the first theory that highlights the role of interest groups in the formation of policies towards international factor movements. ${ }^{4}$ We model the strategic interaction between organized factors competing for protection and the government as a common agency problem in the spirit of Bernheim and Whinston (1986) and Grossman and Helpman (1994). In the first stage of the game, lobbies offer the incumbent politician contribution schedules that are contingent on the degree of protection granted to different factors. In the second stage, the government trades off social welfare against contributions in choosing the optimal policy.

The equilibrium protection level granted to a particular factor depends on the structure of production and on the political characteristics of the economy, according to a modified Ramsey rule. In particular, protection is higher for a lobbying than for a non-lobbying factor, and is increasing in the domestic supply of the factor, while decreasing in the proportion of the population involved in lobbying. ${ }^{5}$ Furthermore, the equilibrium protection level is determined by the degree of complementarity between inputs. For example, suppose that two complementary factors, A and B, both lobby for protection. Admitting more imports of factor A increases the marginal product of factor B. Therefore, factor $\mathrm{B}$ has an incentive to lobby against protection for factor $\mathrm{A}$, to secure a higher wage for itself. More generally, the lobbying of a factor has a detrimental effect on the degree of protection granted to its complements. This argument is reversed in the case of lobbying substitutes.

These results hold irrespective of whether the policy takes the form of a tax or a quantitative restriction. When quotas are used, as for example in the context of immigration, the associated rents are often not captured by the domestic government. We extend our result to allow for any degree of rent capturing as well as for mixed policies where taxes are applied to certain factors and quotas to others. Furthermore, if capturing is complete, we establish a general equivalence result of tariffs and quotas for the strategic environment under consideration.

What are the long run implications of our model? We address this question in the last section of the paper. To that end we consider first the effects of technological progress both in the Home country and in the rest of the world. We show that while the first leads to an increase in protection accompanied by larger factor inflows, the latter leads to higher protection, and a decline in domestic factor employment. We then look at the impact offspring of past immigrants have in the determination of current policy towards factor mobility. It turns out that past immigration will lead to an increase in current protection, and to a reduction in factor inflows.

\footnotetext{
${ }^{4}$ In an interesting recent paper (Blanchard, 2004) develops a trade model in which policy towards FDI is also endogenously determined, as the result of the actions of a welfare maximizing government. Focusing on exportplatform FDI she shows first that source countries have an incentive to unilaterally liberalize trade with the FDI destination country. Interestingly, in a multi-country extension of the original model, she also shows that if preferential tariff treatment is possible, small countries will find it welfare maximizing to subsidize foreign investment in the exporting sector.

${ }^{5}$ This mirrors the results obtained by Grossman and Helpman (1994) for trade in final goods and corresponds in our model to the special case when the production function is additively separable.
} 
While a large body of literature is devoted to understanding the political economy of protection in international trade, ${ }^{6}$ studies that analyze the politics of distortions in international factor movements are rare, and a unified framework has yet to emerge. In most recent contributions, the political economy of migration has been modelled as a univariate median voter decision problem, rather than as the result of the lobbying activity by organized groups. In a very elegant paper, Benhabib (1996) considers for instance the capital and skill requirements that would be imposed on potential immigrants by an income maximizing polity. In his model, the median voter chooses to admit individuals supplying a set of factors (labor, human, and physical capital) that are complementary to the endowments of the natives. The same political process has been used also in the large literature analyzing the impact of immigration on the recipient country's welfare system. ${ }^{7}$

The recent phenomenon of competition for Foreign Direct Investment has so far received limited attention in the political economy literature. In an interesting paper on the subject, Haaparanta (1997) uses a menu auction approach to model intergovernmental bidding wars to attract foreign multinationals. The government uses FDI as a way of reducing unemployment. Intuitive results emerge concerning the distortionary effects of inter-jurisdictional competition, but the model is partial equilibrium in nature and the interaction between domestic capital and FDI is completely ignored.

The rest of the paper proceeds as follows. In Section 2, we describe the factor protection game, while Section 3 provides a characterization of the equilibrium protection structure. In Section 4, we consider quantitative restrictions, and in Section 5 we discuss the long run implications of the model. Section 6 concludes the paper.

\section{The factor protection game}

This section presents our model and describes the factor protection game. Consider a small open economy that faces exogenously given international prices. For simplicity, and since the focus of the paper is on factor movements, let there be only one output good produced from a set of inputs $I=\{1, \ldots, n\}$. Note that with only one output we are abstracting from trade in final goods. Instead we focus on the in- and outflow of the $n$ factors. ${ }^{8}$

Our small country has a population of $M$ domestic residents. Each of them owns only one type of (internationally mobile) factor. Let $M_{i}$ denote the number of domestic agents inelastically supplying factor $i$. Clearly $M=\sum_{i \in I} M_{i}$. We can now define ratios $\alpha_{i}=M_{i} / M$

\footnotetext{
${ }^{6}$ For an overview of this literature, see the surveys by Rodrik (1995), Helpman (1997), and Gawande and Krishna (2003). Facchini (2004) surveys the literature on political economy models of trade and factor mobility.

${ }^{7}$ Among the many interesting papers in this literature, see Mazza and van Winden (1996), Razin et al. (2002), Scholten and Thum (1996), and Razin and Sadka (1999).

${ }^{8}$ It would be interesting to also include multiple final goods, thus allowing for the joint determination of policies towards factor movements and trade. For reasons of tractability and because we want to emphasize the complementarity of factors, this paper analyzes the one sector-many factors case.
} 
that represent the percentage of the population owning factor $i .{ }^{9}$ These ratios will be used as a distribution rule for aggregate profits and tariff revenue later on. Denote by $\ell_{i}$ the domestic supply of input $i$ and by $m_{i}$ the quantity of factor $i$ that is imported (exported if negative). The total supply of factor $i$ available domestically thus amounts to $L_{i}^{S}=i_{I}+m_{i}$. Output is produced from these inputs according to the production function $Y=F\left(L_{1}, \ldots, L_{n}\right)$. Assuming decreasing returns to scale, ${ }^{10}$ we can equivalently represent the production side by means of the corresponding profit function $\pi(\mathbf{w})$. Domestic factor demands $L_{i}^{D}$ can then be derived from this profit function via Hotelling's lemma.

As for prices, we choose aggregate output as the numéraire and normalize its price to one. Let $\mathbf{W}$ be the set of real domestic input price vectors. We bound $\mathbf{W}$ so that each domestic price $w_{i}$ must lie between a minimum $\underline{w}_{i}$ and a maximum $\bar{w}_{i}{ }^{11}$ Furthermore, let $\mathbf{w}=\left(w_{1}, \ldots, w_{j}, \ldots, w_{n}\right)$ be the domestic price vector, while $\mathbf{w}^{*}=\left(w_{1}^{*}, \ldots, w_{j}^{*}, \ldots, w_{n}^{*}\right)$ indicates the vector of real factor prices prevailing on the world market.

Policy towards the inflow and outflow of production factors is modelled as the result of lobbying as in Grossman and Helpman (1994). ${ }^{12}$ That is, the lobbying game takes the form of a menu auction à la Bernheim and Whinston (1986). The lobbying factors ${ }^{13} \Lambda \subseteq I$ submit contribution schedules $B_{i}(\mathbf{w})$ to the government. In other words, these factors specify their monetary contributions contingent on the (entire) domestic factor price vector. Note that depending on the institutional setting, such payments may involve illicit bribes or take the form of legal campaign support. The government, the common agent, or auctioneer in this framework, subsequently grants or denies protection by setting the domestic factor price vector ${ }^{14}$ and collects the contributions from the lobbying factors.

Having described the strategy spaces of the actors, let us turn to their respective payoffs, expressed in monetary terms. Each factor (lobbying or not), receives a gross payment of

$$
g_{i}(\mathbf{w})=w_{i} \ell_{i}+\alpha_{i}\left(\pi(\mathbf{w})+\sum_{k \in I}\left(w_{k}-w_{k}^{*}\right)\left(L_{k}^{D}-\ell_{k}\right)\right) \forall i \in I
$$

\footnotetext{
${ }^{9}$ The assumption that each agent owns only one type of (mobile) factors is convenient because multiple factor ownership would require modelling explicitly the link between the owners of multiple (mobile) factors and the lobby/lobbies that represent them. One possible way of accommodating multiple factor ownership would be to completely forego the introduction of agents. The $\alpha$ 's would then specify an abstract distribution rule across factors.

${ }^{10}$ Alternatively, think of constant returns with an additional fixed factor, land for example. Ownership of this factor would be distributed according to $\alpha$ and agents would earn an additional wage instead of claiming the residual profit.

${ }^{11}$ Notice that although Bernheim and Whinston (1986) consider the case where players bid for a finite set of objects, the analysis carries through also to the case in which the auctioneer can choose from a continuum of actions. See Bernheim and Whinston (1986), footnote 6.

${ }^{12}$ Our framework is of course closely related to theirs, with the generalization that our production function (corresponding to their utility function) allows for substitution and complementarity and the simplification that factor supplies (output supplies in their model) are fixed.

${ }^{13}$ We follow the literature in assuming that the subset of lobbying factors is exogenously given. A theory of the endogenous formation of pressure groups has been proposed by Mitra (1999).

${ }^{14}$ Note that fixing the domestic factor price vector is equivalent to imposing a set of tariffs and subsidies.
} 
where the first term on the right hand side represents its income, and the second its share $\alpha_{i}$ of profits and of the revenue from protection. ${ }^{15}$ Each organized factor seeks to maximize its net payoff $n_{i}(\mathbf{w})=g_{i}(\mathbf{w})-B_{i}(\mathbf{w})$, by choosing a contribution schedule $B_{i}(\mathbf{w})$.

In determining the degree of protection to be granted to each factor, the government weighs the sum of domestic citizens' welfare against the monetary contributions paid by the lobbies. As is standard in this literature-Grossman and Helpman (1996) provide a micro-foundation for this specification-the government's objective takes the following linear form:

$$
S=a \sum_{i \in I} g_{i}(\mathbf{w})+\sum_{i \in \Lambda} B_{i}(\mathbf{w}) a \geq 0
$$

This objective function implies that that the elected politicians value one dollar of contributions in their campaign coffers more than one dollar left with the public. ${ }^{16}$

\section{The equilibrium protection structure}

We are now ready to characterize the equilibrium protection structure resulting from this game. Denote by $\Lambda_{-i}$ the set of lobbying factors minus the $i$ th lobby, $\Lambda \backslash\{i\}$. We are interested in a subgame perfect Nash equilibrium of the factor protection game, defined as follows:

Definition 1. The collection $\left(\left\{B_{i}^{0}(\mathbf{w})\right\}_{i \in \Lambda}, \mathbf{w}^{0}\right)$ is a subgame perfect Nash equilibrium of the factor protection game if $B_{i}^{0}$ is feasible for all $i \in \Lambda$, $\mathbf{w}^{0}$ maximizes $a \sum_{i \in I} g_{i}(\mathbf{w})+\sum_{i \in \Lambda} B_{i}^{0}(\mathbf{w})$, and, given $\left\{B_{j}^{0}(\mathbf{w})\right\}_{j \in \Lambda_{-i}}$, no lobby $i$ has an alternative feasible strategy $B_{i}(\mathbf{w})$ that would yield a higher (net) payoff.

In other words, the collection $\left(\left\{B_{i}^{0}(\mathbf{w})\right\}_{i \in \Lambda}, \mathbf{w}^{0}\right)$ is an equilibrium if each group's schedule is optimal for its members, given the expected contributions of the other lobbies and the policy maker's anticipated choice.

To refine the set of possible equilibria, we follow Grossman and Helpman (1994) and assume that the contributions schedules $\{B(\mathbf{w})\}_{i \in I}$ are differentiable, at least around the equilibrium price vector. This assumption guarantees that the contribution schedules are locally truthful. In other words, around the equilibrium price vector $\left(\mathbf{w}^{0}\right)$, the effect of a marginal change in policy matches the marginal change in the lobbies'

\footnotetext{
15 Note that we implicitly assume that the shares are the same for profits as well as for tariff revenue. If we were to relax this assumption, the qualitative results would carry through as long as the correlation between the two distribution rules is sufficiently high. Since we do not have an informed prior concerning this correlation, we prefer to work with the convenient assumption of identical distribution rules.

${ }^{16}$ To see this point, note that $n_{i}(\mathbf{w})=g_{i}(\mathbf{w})-B_{i}(\mathbf{w})$ if $i \in \Lambda$ and $n_{i}(\mathbf{w})=g_{i}(\mathbf{w})$ if $i \notin \Lambda$. The objective function of the government can then be rewritten as $S=a \sum_{i \in I} n_{i}(\mathbf{w})+(1+a) \sum_{i \in \Lambda} B_{i}(\mathbf{w})$ and every dollar contributed by a lobby is worth $1+a$ dollars to the incumbent politician.
} 
gross welfare. ${ }^{17}$ Using Lemma 2 from Bernheim and Whinston (1986), we can then prove the following

Proposition 1. In an interior equilibrium, the government chooses a domestic price vector $w$ that satisfies

$$
\boldsymbol{w}-\boldsymbol{w}^{*}=\left(\nabla_{w}^{2} \pi\right)^{-1} \boldsymbol{z}=-\nabla^{2} \boldsymbol{F} \boldsymbol{z}
$$

where $\nabla_{w}^{2} \pi$ denotes the Hessian of the profit function with derivatives taken only with respect to factor prices, $\nabla^{2} \boldsymbol{F}$ is the Hessian of the underlying production function, and $\boldsymbol{z}$ a $n \times 1$ column vector whose jth element takes the form

$$
z_{j}=\frac{\left(I_{j}-\alpha_{\Lambda}\right) \ell_{j}}{a+\alpha_{\Lambda}} .
$$

and $I_{j}$ is an indicator that equals 1 if factor $j$ lobbies and 0 otherwise.

Proof. See Appendix A.

To gain further insight, expanding the $j$ th component of Eq. (2) we have

$$
w_{j}-w_{j}^{*}=-\frac{1}{a+\alpha_{\Lambda}} \sum_{i \in I} F_{j i}\left(I_{i}-\alpha_{\Lambda}\right) \ell_{i} \forall j \in I .
$$

Consider first the diagonal elements, i.e. that element in each sum for which $j=i$. Strict concavity of the production function implies that $F_{i i}$ is negative. Therefore, leaving aside the other terms in the sum for a moment, if the factor under consideration lobbies $\left(I_{i}=1\right)$ we see an import tariff (an export subsidy) because $\alpha_{\Lambda} \leq 1$. If, on the other hand, this particular factor does not lobby, then it has to endure an import subsidy (an export tax). The tariff (export subsidy)-or the absolute value of the import subsidy (export tax)-is increasing in $F_{i i}$ and $\ell_{i}$ but decreasing in $a$ and $\alpha_{\Lambda}$. The direction of these effects is intuitive. The more weight the government places on social welfare (parameter $a$ ), the lower the tariff. The larger the share of the domestic population involved in lobbying activities $\left(\alpha_{\Lambda}\right)$, the lower the tariff each lobby obtains because their efforts partially offset each other. The greater the curvature of the production frontier $\left(\left|F_{i i}\right|\right)$, the higher the tariff according to a modified Ramsey rule. And, finally, the greater the domestic supply of a factor, the higher the tariff it can obtain.

Suppose the off-diagonal terms are indeed zero, i.e. $\frac{\partial^{2} F}{\partial w_{i} \partial w_{j}}=\frac{\partial^{2} \pi}{\partial w_{i} \partial w_{j}}=0 \forall i \neq j$. Then the production function is additively separable. We briefly discuss this special case to explore the connection between our result and what Grossman and Helpman (1994) obtain for trade in final goods. Define the proportional tariff imposed on factor $i$ as $t_{i}=\frac{w_{i}-w_{i}^{*}}{w_{i}^{*}}$. Then, for all $i \in I$, these tariffs are implicitly given by

$$
\frac{t_{i}}{1+t_{i}}=\frac{I_{i}-\alpha_{\Lambda}}{a+\alpha_{\Lambda}} \times \frac{\ell_{i} / m_{i}}{\epsilon_{m_{i}, w_{i}}}
$$

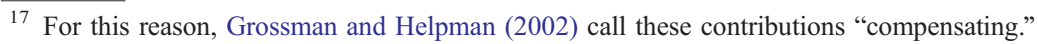


where

$$
\boldsymbol{\epsilon}_{m_{i}, w_{i}}=-\frac{\partial m_{i}}{\partial w_{i}} \times \frac{w_{i}}{m_{i}}
$$

This is exactly analogous to the result obtained by Grossman and Helpman (1994) in their paper where tariffs apply to trade in final goods. ${ }^{18}$

Departing from this special case, let us emphasize that we view a full matrix of substitution (or rather complementary) effects as essential on the production side. If two factors $i$ and $j$ are complements, then $F_{i j}>0$, whereas if another pair of factors $i$ and $k$ are substitutes, then $F_{i k}<0 .{ }^{19}$ How do these relationships affect the equilibrium protection levels? A lobbying complement will have a detrimental effect on the protection level granted to the other factor. ${ }^{20}$ Letting in more imports increases the marginal product of the complement. The complement therefore has an incentive to lobby against protection for the other factor to secure a higher marginal product and consequently real wage for itself. A lobbying substitute, on the other hand, positively affects the other factor's equilibrium protection level because letting in more imports of either factor would not only decrease the marginal product-and thereby the real wage-of the factor itself, but also that of its substitute. The substitute therefore also has an incentive to lobby for protection on behalf of its "partner." In the extreme case of perfect substitutes we could combine both into a single factor and the increased weight of this new single factor would lead to a higher tariff as seen above. If the complement or substitute does not lobby then the effects are reversed. The existence of a complement (substitute) makes demand for the factor in question less (more) elastic. The government will therefore set a higher (lower) tariff than it would have in the additively separable case.

Given the role of complementarities among factors in shaping policy, it seems natural to ask whether our equilibrium is coalition proof. To address this question, we use the results established by Bernheim and Whinston (1986) for (globally) truthful contribution schedules. As we have already stressed, the assumption that the contribution schedules used by the agents are differentiable implies that they are locally truthful around the equilibrium point. Globally truthful schedules exhibit this property everywhere, i.e. take the form $B_{i}^{T}(\mathbf{w}, B)=\max \left\{0, g_{i}(\mathbf{w})-B\right\}$ for some $B$ determined endogenously in the model. Since the gross pay-off functions are differentiable, truthful schedules are differentiable as well-except potentially at the point where they become zero. Bernheim and Whinston show that each bidder's best reply correspondence contains a truthful schedule. Furthermore, truthful equilibria are efficient and any efficient outcome can be supported as a truthful Nash equilibrium. Finally, all truthful Nash equilibria are coalition proof.

\footnotetext{
18 In their framework, the assumptions that lead to this result are the existence of sector specific factors and a quasilinear, separable utility function.

19 There is an alternative definition of gross substitutes that is based on the factor demand functions. Note that our definition does not suffer from the inconsistency usually associated with "uncompensated" effects.

${ }^{20}$ Gawande and Bandyopadhyay (2000) and McCalman (2004), modelling the role of lobbying by the producers of one intermediate input in the trade context, show that a similar effect obtains between the one input and output. However, in such a framework, they cannot address the general effects we are discussing here.
} 
Based on these properties, they advocate truthful equilibria as "appealing, perhaps even focal."

Let us now turn our attention to the contribution schedules. How much does a particular lobby pay the government to obtain its preferred policy? To answer this question suppose the factor $i \in \Lambda$ did not lobby or offered a zero contribution. Given the equilibrium contribution schedules of the other lobbies, the government would then choose a price vector

$$
\mathbf{w}^{-i} \in \arg \max _{\mathbf{w} \in \mathbf{W}} a \sum_{i \in I} g_{i}(\mathbf{w})+\sum_{i \in \Lambda_{-i}} B_{i}^{0}(\mathbf{w})
$$

In equilibrium-with factor $i$ lobbying-the government must attain at least this payoff level. Since lobby $i$ will not contribute more than necessary, it follows that

$$
a \sum_{i \in I} g_{i}\left(\mathbf{w}^{-i}\right)+\sum_{i \in \Lambda_{-i}} B_{i}^{0}\left(\mathbf{w}^{-i}\right)=a \sum_{i \in I} g_{i}\left(\mathbf{w}^{0}\right)+\sum_{i \in \Lambda} B_{i}^{0}\left(\mathbf{w}^{0}\right)
$$

and hence

$$
B_{i}^{0}\left(\mathbf{w}^{0}\right)=a \sum_{i \in I} g_{i}\left(\mathbf{w}^{-i}\right)+\sum_{i \in \Lambda_{-i}} B_{i}^{0}\left(\mathbf{w}^{-i}\right)-a \sum_{i \in I} g_{i}\left(\mathbf{w}^{0}\right)-\sum_{i \in \Lambda_{-i}} B_{i}^{0}\left(\mathbf{w}^{0}\right)
$$

By optimality of $\mathbf{w}^{-i} B_{i}^{0}\left(\mathbf{w}^{0}\right)$ must be (weakly) positive. We can therefore conclude that all lobbies pay non-negative contributions in equilibrium. ${ }^{21}$

If the government of the receiving country is not able to discriminate between different types of labor and/or capital, it might decide to implement the same level of protection for a group of factors. How will this restriction affect the equilibrium outcome?

Notice first that if we focus our analysis on equilibria in which players use globally truthful contributions schedules, the factors subject to the common tariff will continue to lobby separately. This is the case because even in this new game, in which the government implements a lower-dimensional policy-vector, the equilibrium is coalition-proof, as shown in Theorem 3 of Bernheim and Whinston (1986).

As for the determination of the equilibrium policy outcome, suppose next, for simplicity, that only two factors $j \in C=\{y, z\}$ are subject to a common policy. Furthermore, by appropriate choice of units, assume that the world factor prices $w_{y}^{*}$ and $w_{z}^{*}$ are equal. Focusing on the case of a separable production function, and following the same argument as in the Proof of Proposition $1,{ }^{22}$ we can derive the equilibrium protection structure as described in the following

\footnotetext{
21 If we want to go beyond this simple result-contributions could not be negative, after all--we again need to focus on globally truthful contribution schedules. One can then solve for the reservation utilities of all lobbies and subsequently for their actual contribution schedules. See also Mitra (1999) for a characterization.

22 See the Appendix A.
} 
Proposition 2. In an interior equilibrium, the government chooses a (n-1)-dimensional domestic price vector $\boldsymbol{w}^{C}$ such that

$$
\begin{aligned}
& w_{j}^{C}-w_{j}^{*}=-\frac{1}{a+\alpha_{\Lambda}} F_{j j}\left(I_{j}-\alpha_{\Lambda}\right) \ell_{j} \forall j \in I \backslash C . \\
& w_{c}^{C}-w_{c}^{*}=-\frac{1}{a+\alpha_{\Lambda}} \frac{\left(I_{y}-\alpha_{\Lambda}\right) \ell_{y}}{1 / F_{y y}+1 / F_{z z}}-\frac{1}{a+\alpha_{\Lambda}} \frac{\left(I_{z}-\alpha_{\Lambda}\right) \ell_{z}}{1 / F_{y y}+1 / F_{z z}} .
\end{aligned}
$$

Notice that the factors not subject to the restriction continue to receive the same amount of protection as in Eq. (3). In other words $w_{j}-w_{j}^{*}=w_{j}^{C}-w_{j}^{*}$ for all $j \in I \mid C$. More interestingly, the common tariff $\left(w_{c}^{C}-w_{c}^{*}\right)$ for factors $y$ and $z$ turns out to be a weighted average of the original tariffs:

$$
\begin{aligned}
w_{c}^{C}-w_{c}^{*}= & \frac{\partial L_{y} / \partial w_{y}}{\partial L_{y} / \partial w_{y}+\partial L_{z} / \partial w_{z}}\left(w_{y}-w_{y}^{*}\right) \\
& +\frac{\partial L_{z} / \partial w_{z}}{\partial L_{y} / \partial w_{y}+\partial L_{z} / \partial w_{z}}\left(w_{z}-w_{z}^{*}\right)
\end{aligned}
$$

In other words, the more responsive is a factor demand to changes in the own price, the more weight that factor receives in the setting of the common tariff, and the closer is the common level of protection to the original one enjoyed by this factor.

\section{Quotas}

So far we have measured protection as the difference between the world market and domestic prices. For a factor such as capital this seems natural. Taxes on external capital transactions have been used to manage financial flows. ${ }^{23}$ Central banks at times impose extra deposit requirement on foreign loans. In addition, fiscal incentives to attract foreign direct investment are a global phenomenon that has become more and more relevant over the last decade. ${ }^{24}$ But tariffs constitute only one of the policy instruments available to governments for controlling the international flow of production factors. Where the

\footnotetext{
23 For a historical perspective on the use of capital controls, see Cooper (1999).

24 According to Oman (2000) "Data on the direct financial and/or fiscal 'cost-per-job' of incentives received by investors in the automobile industry reveal orders of magnitude [...] that often exceeds \$100,000." Another example of the effectiveness of low corporate income tax rates in attracting FDI is given by the recent Irish experience (Barry et al., 1999).
} 
migration of labor is concerned, quotas seem to be the norm and immigration taxes are rare. $^{25}$

While it is natural to assume that the revenues from tariffs are fully captured by the domestic government, this seems less appropriate when it comes to quantitative restrictions. Consequently, we allow for the possibility that only part of the quota rent is captured, and the remainder goes to the incoming factor. This reflects the fact that while it is common for immigrants to receive a lower wage than equally skilled natives, it is also true that their compensation in the destination country is higher than in their country of origin. $^{26}$

Let us start by describing the quota game. Define $\phi(\mathbf{w}) \equiv-\nabla_{\mathbf{w}} \pi: \mathbf{W} \rightarrow \mathbf{L}$. In other words, $\phi$ denotes the negative gradient of the profit function which, by Hotelling's Lemma, equals the factor demands. Furthermore, let $\mathbf{L}^{*} \equiv \operatorname{Range}(\phi(\mathbf{W}))$. Then, under the quota game, every organized lobby presents the government with a contribution schedule $\tilde{\mathrm{B}}_{i}(\mathbf{L})$, that is, a function of the vector of factor quantities $\mathbf{L}$. The government, on the other hand, chooses factor quantities (and thereby implicitly the quotas) and collects the contributions from the lobbies. In terms of payoffs, every lobby receives

$$
\tilde{g}_{i}(\mathbf{L})=\phi_{i}^{-1}(\mathbf{L}) \ell_{i}+\alpha_{i}\left(\pi\left(\phi^{-1}(\mathbf{L})\right)+\sum_{k \in I} \gamma k\left(\phi_{k}^{-1}(\mathbf{L})-w_{k}^{*}\right)\left(\mathbf{L}_{k}^{D}-\ell_{k}\right)\right),
$$

where $\gamma_{k}$ denotes the percentage of rent captured by the government from a quota on inflows of factor $k$. The government's objective function is now given by

$$
\tilde{S}=a \sum_{i \in I} \tilde{g}_{i}(\mathbf{L})+\sum_{i \in \Lambda} \tilde{B}_{i}(\mathbf{L}) .
$$

A subgame perfect Nash Equilibrium of this quota game is defined as follows:

Definition 2. The collection $\left(\left\{\tilde{B}_{i}^{0}(\mathbf{L})\right\}_{i \in \Lambda}, \mathbf{L}^{0}\right)$ is a subgame perfect Nash equilibrium of the quota game if $\tilde{B}_{i}^{0}$ is feasible for all $i \in \Lambda, \mathbf{L}^{0}$ maximizes $a \sum_{i \in I} \tilde{g}_{i}(\mathbf{L})+\sum_{i \in L} \tilde{B}_{i}^{0}(\mathbf{L})$.and, given $\left\{\tilde{B}_{j}^{0}(\mathbf{L})\right\}_{j \in \Lambda_{-i}}$, no lobby $i$ has an alternative feasible strategy $\tilde{B}_{i}(\mathbf{L})$ that would yield a higher (net) payoff.

As a preliminary step we establish the following result.

Lemma 1. Let $\boldsymbol{W}_{J}$ be a subset of $\boldsymbol{W}$ where $J \subset I$ components are fixed, and similarly define $\boldsymbol{L}_{J} \subseteq \boldsymbol{L}$ and $\boldsymbol{L} * \subseteq \boldsymbol{L}^{*}$. Then, for all $J$, the mapping $\phi_{J}: \boldsymbol{W}_{J} \rightarrow \boldsymbol{L}_{J}\left(=\boldsymbol{L}_{J}^{*}\right)$ is a bijection.

\footnotetext{
25 It is worth pointing out, though, that many tax codes (the US is no exception) include special provisions for foreign workers which amount to an implicit immigration tax. Furthermore, during earlier waves of mass migration, the use of fiscal instruments to control inflows of foreign workers was rather common. The United States, for example, introduced a head tax of 50 cents per migrant in 1882 , that was progressively raised to $\$ 8$ in 1917. Canada was even more proactive in using taxes and subsidies to control the composition of the immigrant population. In 1870, it introduced a travel fund of C\$ 30 per adult for Mennonites that agreed to build settlements, while in 1885 an Immigration Act was passed by Parliament to "restrict and regulate Chinese immigration" by assessing a tax of C\$ 50 per head. This tax was raised to C\$ 200 in 1910. For more details on past immigration policies we refer the reader to the interesting work of Timmer and Williamson (1996).

${ }^{26}$ Note that in this paper we do not endogenize the choice of the policy instrument to be used, or the degree of rent capturing. Maggi and Rodriguez-Clare (2000) address this question in the trade context.
} 
Proof. See Appendix A.

Using Lemma 1 and taking into account partial rent capturing, we can derive the following result.

Proposition 3. In an interior equilibrium under partial capturing the government chooses a vector of quantitative restrictions $q$ or equivalently the domestic employment vector $\boldsymbol{L}=\boldsymbol{q}+\ell$ that satisfies

$$
\Gamma\left(\phi^{-1}(\boldsymbol{L})-\boldsymbol{w}^{*}\right)=\left(\nabla_{\boldsymbol{w}}^{2} \pi\right)^{-1} \tilde{\boldsymbol{z}}=-\nabla^{2} \boldsymbol{F} \tilde{\boldsymbol{z}}
$$

where $\Gamma$ is a diagonal matrix with elements $\left\{\gamma_{1}, \ldots, \gamma_{n}\right\}$ and $\tilde{\mathbf{z}}$ a $(n \times 1)$ column vector whose jth element is

$$
\tilde{z}_{j}=z_{j}-\left(1-\gamma_{j}\right)\left(L_{j}-\ell_{j}\right)
$$

To explore the effects of partial capturing on the tariff-equivalent of the quota, ${ }^{27}$ let us expand the $j$ th component of Eq. (7)

$$
\phi_{j}^{-1}(\mathbf{L})-w_{j}^{*}=-\frac{1}{\gamma_{j}} \sum_{i \in I} F_{j i}\left(\frac{\left(I_{i}-\alpha_{\Lambda}\right) \ell_{i}}{a+\alpha_{\Lambda}}-\left(1-\gamma_{i}\right)\left(L_{i}-\ell_{i}\right)\right) \forall j \in I
$$

First, consider the case of full capturing of the quota rent. The RHS of Eq. (8) then coincides with the solution we found for price restrictions in Eq. (3). This establishes the equivalence of price and quantity restrictions which is familiar from the competitive trade context. Nevertheless, this result is remarkable here given that we are modelling the strategic interaction among different groups. In fact we can show the following stronger result:

Proposition 4. The tariff game is strategically equivalent to the quota game.

Proof. Define $\tilde{\mathrm{B}}_{i}(\mathbf{L})=B_{i}\left(\phi^{-1}(\mathbf{L})\right)$ for all $i \in \Lambda$ and apply Lemma 1 .

The intuition for this result is straightforward. Lemma 1 guarantees that the government can control the outcome in the factor market-i.e. the combination of factor employment and prices-by either setting domestic prices or domestic employment. The lobbies' contributions depend only on the outcome, not on the policy variable used to achieve it. $^{28}$

Coming back to Eq. (8), let us now discuss the case in which rent capturing is partial. We can see that the effect of reduced rent capturing works through two channels. On the one hand, when rent capturing is partial, the decrease in revenues equally affects everyone. However, the government prefers to see a disproportionate share of this cost being born by the unorganized groups and wants to protect the organized sectors, hence tightening

\footnotetext{
27 Notice that strictly speaking this expression is appropriate only under full capturing as we will show below. 28 Notice that a similar result can be obtained also for the original Grossman and Helpman (1994). See Facchini et al. (2003).
} 
policy. This effect is captured by the inverse of $\gamma_{j}$. As for the second channel, under full capturing, the effect of a change in protection on government revenue is completely offset by an opposing effect on profits. When capturing is partial, this is no longer the case. Whereas the effect on profit is the same as before, the implied change in revenues falls short of offsetting the former. This renders protection less attractive.

Finally, note that Lemma 1 can accommodate also the case in which the government chooses a mix of quotas for some factors and price restrictions for others. The resulting policies-tariffs or tariff equivalents-are then determined by the right hand side of Eq. (8), with $\gamma_{j}=1$ for every factor $j$ that is subject to a tax.

\section{Long run effects}

Even though our basic model is static in nature, it is interesting to analyze its long run implications by means of a series of comparative static exercises. First, we focus on the effects of technological progress that takes place in the home country as well as in the rest of the world. We show that Hicks-neutral technological progress in the home country tends to increase protection and factor employment, whereas-by a similar logic-an increase in productivity abroad leads to a decline in domestic factor employment.

Subsequently, we consider the long run implications of factor mobility when the owners of the mobile factor actually settle in the destination country and (a percentage of) their offspring are naturalized. We find that the extent of protection granted to the domestic factor (including the immigrants' offspring) increases and that, depending on the fraction of the offspring obtaining naturalization, this leads to a reduced inflow of immigrants, or potentially to an outflow if the naturalization rate is very high. In carrying out these analyses we focus on the separable case and point out the additional implications of complementarity and substitutability whenever it is appropriate. Furthermore, for simplicity, we concentrate on import competing factors that are actively lobbying. ${ }^{29}$

\subsection{Technological change}

Let us first consider technological progress in the home country that is of the Hicksneutral type. ${ }^{30}$ Formally, the production function now takes the form $Y=A(t) F\left(L_{1}, \ldots, L_{n}\right)$, where $A(t)$ describes the level of technology that is available at time $t$. How does an increase in $A(t)$ affect the policy towards factor inflows as well as the very size of the inflows themselves? Without loss of generality, let us assume that $A(t=1)>A(t=0)=1$. Holding the employment vector fixed, this will lead to an increase in aggregate output by a factor of $A(1)$, as well as to an equi-proportionate increase in the marginal product of each production factor.

\footnotetext{
29 The extension of the analysis to include the three other possible cases is straightforward.

${ }^{30}$ Of course, technological progress need not be Hicks-neutral. Indeed, recent evidence for industrialized countries suggests that it is skill-biased. While explicitly introducing skill bias would affect the magnitude of our findings, it would not change our results qualitatively.
} 
As for the endogenous determination of policy towards factor movements, Eq. (3) now becomes

$$
w_{j}^{\prime}-w_{j}^{*}=-\frac{A(t)}{a+\alpha_{\Lambda}} F_{j j}\left(I_{j}-\alpha_{\Lambda}\right) \ell_{j} \forall j \in I .
$$

It follows that an increase in $A$ leads to an increase in the endogenous domestic factor price vector from $\mathbf{w}$ to $\mathbf{w}^{\prime}$. In particular, $\mathbf{w}^{\prime}-\mathbf{w}^{*}=A(1)\left(\mathbf{w}-\mathbf{w}^{*}\right)$, which implies that the factor price vector increases less than proportionally, i.e. $\mathbf{w}^{\prime} \leq A(1) \mathbf{w} .^{31}$ Recall that the marginal product, on the other hand, increases proportionally with $A$ when employment is held constant. Hence, in order to restore the first order condition for profit maximization, the marginal product will have to decrease, implying a higher equilibrium factor employment. We can summarize this argument as follows:

Proposition 5. Under separability of the production function, Hicks-neutral technological progress leads to an increase in protection and to higher employment for each of the lobbying factors.

How will this result be affected if we allow for substitutability and complementarity between production factors? Consider the case where factors $i$ and $j$ are complements. An inflow of factor $j$ then tends to increase, ceteris paribus, the marginal product of factor $i$. This effect works against the required decrease in marginal product. Consequently, the inflow of factor $i$ necessary to restore optimality will need to be larger. If factor $i$ and $j$ are substitutes instead, the effects are reversed and the additional inflows will be smaller.

So far we have considered technological change in the home country. Alternatively, we could analyze the effects of an increased productivity in the rest of the world. First note that technological change abroad will be reflected in the vector of world factor prices, $\mathbf{w}^{*}$. In particular, technological progress in the rest of the world translates into higher world factor prices and, as can be seen from Eq. (3), this price change is transmitted one-to-one to domestic factor prices. In order to restore the first order conditions for profit maximization, the marginal product of each factor has to increase, which requires a decline in factor employment. In other words, technical progress in the rest of the world is the mirror image of technological change at home.

\subsection{Lasting effects of immigration}

In the case of labor services, the inflow of the production factor is often accompanied by the physical relocation of the owners to the destination country. ${ }^{32}$ In the basic version of our model, the welfare of immigrants is not included in the objective function of the government, nor are immigrants allowed to lobby. While this assumption is realistic in the short run, over longer time horizons immigrants (and their offspring) might be naturalized

\footnotetext{
31 Notice that we are implicitly assuming that the third derivatives of the production function are well-behaved so that the direct effects dominate.

32 This could also be the case for other factor inflows - many traditional immigration countries, for example, allow the immigration of entrepreneurs provided that they invest enough capital in the country.
} 
and should therefore be treated as natives in the model. How will the naturalization process affect the equilibrium policy?

To keep the dynamic model simple and tractable, let us assume that all agents live for only one period. At the end of each period, domestic and foreign-born residents alike have exactly one child. Furthermore, assume that a share $\mu$ of the immigrants' offspring are naturalized, i.e. they become citizens of the country to which their parents had migrated, and behave exactly like their domestic counterparts. Formally, this implies that $\ell_{j}(t)=\ell_{j}(t-1)+\mu m_{j}(t-1)$, for any period $t$. Assuming also that the government optimizes period by period and cares only about the current generation, the equilibrium protection policy can be described as follows

$$
w_{j}(t)-w_{j}^{*}=-\frac{1}{a+\alpha_{\Lambda}} F_{j j}\left(I_{j}-\alpha_{\Lambda}\right)\left[\ell_{j}(t-1)+\mu m_{j}(t-1)\right] \forall j \in I .
$$

According to Eq. (10), the increased domestic factor supply will lead to an increase in the absolute value of protection. To restore the first order condition for profit maximization, the increase in the domestic price requires a corresponding increase in the marginal product of the factor, and hence total employment must decline in comparison to the previous period. Depending on the value of $\mu$, this will lead to a reduced inflow of immigrants, or in the extreme to an outflow if the share of naturalized immigrants is close to one. The reason for this result is that, while allowing immigrants or their offspring to become citizens increases the demand for protection, it simultaneously reduces the need for additional inflows.

\section{Conclusion}

In this paper, we have addressed two questions: Why do we observe so much government intervention in cross-border factor markets? What are its determinants? To provide an answer, we have developed a political economy model of international factor mobility, in which policy is endogenously determined by the interaction of an electorally driven government and domestic pressure groups. In a menu auction à la Bernheim and Whinston (1986), organized factors present the government with contribution schedules that specify payments which depend on the degree of protection to be granted by the government. The government then trades off social welfare against contributions, choosing the protection levels-either in terms of prices or quantities-for all the different factors. Since we allow for multiple factors, our model is of considerable generality. Both immigration as well as FDI policy can be explored within our framework. Solving for the equilibrium protection levels reveals how tariffs or quotas that apply to the inflow of foreign factors are determined: they depend, in an important way, on the production structure, the domestic supply of the different factors, and a set of political characteristics of the destination country.

The model can be taken to the data, and a preliminary attempt has been undertaken in Facchini and Willmann (2004). In that paper, we estimate the model using a cross section of 20 OECD countries and taking advantage of the variability in policies implemented at the national level. The preliminary results we obtain are encouraging and broadly support the 
model developed in this paper. In particular, our findings highlight both the role of lobbying as well as the importance of complementarities between factors in shaping policy.

As for further theoretical work, we can think of at least three directions in which the model can be extended. One interesting avenue for future research is to include multiple final goods and to consider explicitly the interaction between policy towards factor mobility and trade restrictions in a setup in which lobbying activities play a role on both dimensions. The question that could be addressed in such a framework is to what extent the two sets of instruments are political substitutes/complements. Our framework could also be generalized by considering multiple countries in order to model the domestic determinants of inter-jurisdictional competition for production factors. This seems to be an important issue, given the experiences of many countries that have been engaged in bidding wars to attract foreign direct investment. Finally, the multi-factor setup we have developed in this paper could be used to analyze the spillovers induced by different policies when two or more countries consider liberalizing factor movements within a common market, while retaining protection towards vis-à-vis non-member countries. This is the subject of discussions in the European Union, where members retain ample discretionary power when it comes to exterior migration and FDI policies. ${ }^{33}$

\section{Acknowledgement}

We would like to thank B. Douglas Bernheim, Peter J. Hammond, and Assaf Razin for their advice and encouragement. Very useful comments were provided by Robert Cumby, Xenia Matschke, Hiro Nakata, Luigi Pistaferri, Luis Rayo, Ravi Singh, Valter Sorana, Marco Sorge, and Cecilia Testa, as well as by seminar audiences at Amsterdam, Autonoma de Barcelona, Carlos III, Essex, Georgetown, Illinois, INSEAD, Munich, Pompeu Fabra, UC Santa Cruz, Stanford, Tilburg, Western Ontario, at ERWIT 2001 and the ES 2002 winter meetings in Atlanta. We especially thank the editor and two anonymous referees for suggestions that substantially improved the paper. The first author gratefully acknowledges financial support provided by a John M. Olin Foundation Dissertation Fellowship. All remaining errors are ours.

\section{Appendix A}

\section{A.1. Proof of Proposition 1}

Proof. Concentrating on differentiable schedules, condition (ii) of Lemma 2 from Bernheim and Whinston (1986) translates into

$$
a \sum_{k \in I} \nabla g_{k}\left(\mathbf{w}^{0}\right)+\sum_{k \in \Lambda} \nabla B_{k}^{0}\left(\mathbf{w}^{0}\right)=0
$$

\footnotetext{
33 For a first attempt at this task, see Facchini and Testa (2004).
} 
and condition (iii) into

$$
a \sum_{k \in I} \nabla g_{k}\left(\mathbf{w}^{0}\right)+\sum_{k \in \Lambda} \nabla B_{k}^{0}\left(\mathbf{w}^{0}\right)+\nabla g_{i}\left(\mathbf{w}^{0}\right)-\nabla B_{i}^{0}\left(\mathbf{w}^{0}\right)=0 \forall i \in \Lambda
$$

Combining Eqs. (11) and (12) and we have

$$
\nabla g_{i}\left(\mathbf{w}^{0}\right)-B_{i}^{0}\left(\mathbf{w}^{0}\right) \forall i \in \Lambda
$$

which shows that the contribution schedules chosen by the lobbies are locally truthful, i.e. the contribution a lobby is willing to pay for a marginal change in the domestic price vector is equal to the marginal change in its gross welfare in a neighborhood of the equilibrium price vector. Summing Eq. (13) over $i \in \Lambda$ and substituting into Eq. (11) gives

$$
a \sum_{i \in I} \nabla g_{i}\left(\mathbf{w}^{0}\right)+\sum_{i \in \Lambda} \nabla g_{i}\left(\mathbf{w}^{0}\right)=0
$$

Taking a closer look at the gradient of the factors' gross payoff function, we note-cf. Eq. (1)-that

$$
\frac{\partial g_{i}(\mathbf{w})}{\partial w_{j}}=\delta_{i j} \ell_{j}+\alpha_{i}\left(-\ell_{j}+\sum_{k \in I}\left(w_{k}-w_{k}^{*}\right) \frac{\partial L_{k}^{D}}{\partial w_{j}}\right) \forall i, j \in I,
$$

where the indicator

$$
\delta_{i j}= \begin{cases}1 & \text { if } i=j \\ 0 & \text { otherwise }\end{cases}
$$

Using this derivative we can rewrite the rows of the two sums from Eq. (14) as

$$
\begin{aligned}
& \sum_{i \in \Lambda} \frac{\partial g_{i}\left(\mathbf{w}^{0}\right)}{\partial w_{j}}=I_{j} \ell_{j}+\alpha_{\Lambda}\left(-\ell_{j}+\sum_{i \in I}\left(w_{i}-w_{i}^{*}\right) \frac{\partial L_{i}^{D}}{\partial w_{j}}\right) \forall j \\
& \sum_{i \in I} \frac{\partial g_{i}\left(\mathbf{w}^{0}\right)}{\partial w_{j}}=\sum_{i \in I}\left(w_{i}-w_{i}^{*}\right) \frac{\partial L_{i}^{D}}{\partial w_{j}} \forall j
\end{aligned}
$$

where

$$
\alpha_{\Lambda}=\sum_{i \in \Lambda} \alpha_{i} \text { and } I_{j}= \begin{cases}1 & \text { if factor } j \text { is lobbies } \\ 0 & \text { otherwise }\end{cases}
$$

Substituting Eqs. (15) and (16) into Eq. (14) results in a system of equations that we solve for the column vector of equilibrium protection, thus establishing the result. 


\section{A.2. Proof of Lemma 1}

Proof. Consider the two price vectors $\mathbf{w}_{J}, \tilde{\mathbf{w}}_{J} \in \mathbf{W}$ and, without loss of generality, assume that the two vectors share the same first $j$ components, i.e.

$$
\mathbf{w}_{J}=\left(\begin{array}{c}
w_{1}^{*} \\
\cdots \\
w_{j}^{*} \\
w_{j+1} \\
\cdots \\
w_{n}
\end{array}\right) \quad \tilde{\mathbf{w}}_{J}=\left(\begin{array}{c}
w_{1}^{*} \\
\cdots \\
w_{j}^{*} \\
\tilde{w}_{j+1} \\
\cdots \\
\tilde{w}_{n}
\end{array}\right)
$$

where $w_{j+k} \neq \tilde{\mathrm{w}}_{j+k} \forall 0<k \leq n-j$. Suppose now that $\phi_{J}\left(\mathbf{w}_{J}\right)=\phi_{J}\left(\tilde{\mathrm{w}}_{J}\right)$. This implies that

$$
\left(\mathbf{w}_{J}-\tilde{\mathbf{w}}_{J}\right)\left(\phi_{J}\left(\mathbf{w}_{J}\right)-\phi_{J}\left(\tilde{\mathbf{w}}_{J}\right)\right)=0 .
$$

But this contradicts the fact that $\phi_{J}$ is monotonic by virtue of $\pi$ being strictly convex. $^{34}$

\section{References}

Barry, F., Bradley, J., O’Malley, E., 1999. Indigenous and foreign industry: characteristics and performance. In: Barry, F. (Ed.), Understanding Ireland's economic growth. MacMillan, London, pp. 41-68.

Benhabib, J., 1996. On the political economy of immigration. European Economic Review 40, 1737-1743.

Bernheim, B.D., Whinston, M.D., 1986. Menu auctions, resource allocation, and economic influence. Quarterly Journal of Economics 101, 1-31.

Blanchard, E.J., 2004. Foreign Direct Investment, endogenous tariffs and preferential trade arrangements. Mimeo, University of Wisconsin, Madison.

Briggs, V.J., 1998. Income disparity and unionism: the workplace influences of post-1995 immigration policy. In: Auerbach, J.A., Belous, R.S. (Eds.), The Inequality Paradox: Growth of Income Disparity. National Policy Association, pp. 112-132.

Cooper, R.N., 1999. Should capital controls be banished? Brookings Papers on Economic Activity, 89-125.

Facchini, G., 2004. The political economy of international trade and factor mobility: a survey. Journal of Economic Surveys 18, 1-31.

Facchini, G., Testa, C., 2004. Why Join a Common Market? Mimeo, University of Illinois at Urbana Champaign. Facchini, G., Willmann, G., 2004. The Political Economy of International Factor Mobility: An Empirical Test. Mimeo, University of Illinois at Urbana Champaign.

Facchini, G., Van Biesebroeck, J., Willmann, G., 2003. Protection for Sale with Imperfect Rent Capturing. Mimeo, University of Illinois at Urbana Champaign.

Gawande, K., Bandyopadhyay, U., 2000. Is protection for sale? Evidence on the Grossman-Helpman theory of endogenous protection. Review of Economics and Statistics 82, 139-152.

Gawande, K., Krishna, P., 2003. The political economy of trade policy: Empirical approaches. In: Choi, E.K., Harrigan, J. (Eds.), Handbook of International Trade. Blackwell Publishing, pp. 213-250.

Goldsborough, J., 2000. Out-of-control immigration. Foreign Affairs 79, 89-101.

Grossman, G.M., Helpman, E., 1994. Protection for sale. American Economic Review 84, 833-850.

Grossman, G.M., Helpman, E., 1996. Electoral competition and special interests politics. Review of Economic Studies $63,265-286$.

\footnotetext{
${ }^{34}$ For details of this last step, see Hildenbrand (1994, Appendix 1).
} 
Grossman, G.M., Helpman, E., 2002. Special Interest Politics. MIT Press, Boston.

Haaparanta, P., 1997. Competition for foreign direct investment. Journal of Public Economics 63, 141-153.

Helpman, E., 1997. Politics and trade policy. In: Kreps, D.M., Wallis, K.F. (Eds.), Advances in Economics and Econometrics: Theory and Applications, vol. 1. Cambridge, pp. 19-45.

Hildenbrand, W., 1994. Market Demand: Theory and Empirical Evidence. Princeton University Press, Princeton, N.J.

Maggi, G., Rodriguez-Clare, A., 2000. Import penetration and the politics of trade protection. Journal of International Economics 51, 287-304.

Mazza, I., van Winden, F., 1996. A political economic analysis of labor migration and income redistribution. Public Choice 88, 333-363.

McCalman, P., 2004. Protection for sale and trade liberalization: an empirical investigation. Review of International Economics 12, 81-94.

Mitra, D., 1999. Endogenous lobby formation and endogenous protection: a long-run model of trade policy determination. American Economic Review 89 (5), 1116-1134.

Oman, C., 2000. Policy Competition for Foreign Direct Investment. OECD, Paris.

Razin, A., Sadka, E., 1999. Migration and pension with international capital mobility. Journal of Public Economics 74, 141-150.

Razin, A., Sadka, E., Swagel, P., 2002. Tax burden and migration: a political economy theory and evidence. Journal of Public Economics 85, 167-190.

Rodrik, D., 1995. Political economy of trade policy. In: Grossman, G.M., Rogoff, K. (Eds.), Handbook of international economics, vol. 3. North Holland, Amsterdam, pp. 1457-1494.

Scholten, U., Thum, M., 1996. Public pension and immigration policy in a democracy. Public Choice 66, $347-361$.

Timmer, A.S., Williamson, J.G., 1996. Racism, xenophobia or markets? The political economy of immigration policy prior to the thirties. NBER WP 5867. 